\title{
Peroxidase mimicking DNAzymes degrade graphene oxide
}

\author{
Rajendra Kurapati, Alberto Bianco*
}

University of Strasbourg, CNRS, Immunology, Immunopathology and therapeutic chemistry, UPR 3572, 67000 Strasbourg, France

Corresponding authors: E-mail: $\underline{\text { a.bianco@ibmc-cnrs.unistra.fr }}$

Keywords: Carbon nanomaterials, degradation, DNA, self-assembly, catalysis 


\begin{abstract}
DNAzymes made of supramolecular guanine-rich G-quadruplexes and hemin are attracting a lot of interest due to their peroxidase activity mimicking the natural enzyme horseradish peroxidase (HRP). Herein, we demonstrate that DNAzyme consisting PS2.M-hemin complex can be an alternative to natural HRP for the oxidation and degradation of graphene oxide (GO). The degradation of GO sheets was carried out by incubating the PS2.M-hemin complex in the presence of hydrogen peroxide for 30 days. The degradation of GO has been confirmed using transmission electron microscopy and 2d Raman mapping. The current study suggests that peroxidase activity of DNAzymes is similar to HRP and it is able to degrade carbon-based nanomaterials.
\end{abstract}




\section{Introduction}

Catalytic nucleic acids are increasingly gaining interests for biosensing, DNA machineries and in the field of biocatalysis in aqueous and non-aqueous media. ${ }^{1,2}$ The catalytic DNA oligonucleotides have the ability to perform specific chemical reactions similar to that of biological enzymes. ${ }^{3,4}$ This type of DNA contains either a supramolecular structures made of metal complexes and double-helical DNA molecules, or single-stranded DNA sequences (e.g. coined deoxyribozymes, or DNAzymes). ${ }^{5,}{ }^{6}$ In particularly, G-quadruplex-DNA/hemin [iron (III)-protoporphyrin IX] complexes are a well-known class of DNAzymes with specific catalytic activity mimicking horseradish peroxidase. ${ }^{7-10}$ Hemin is a ubiquitous metabolic cofactor with various cellular functions, including electron transfer, like into natural peroxidase (HRP, myeloperoxidase (MPO), and others). ${ }^{11}$ G-quadruplexes are folded structures formed by singlestranded guanine-rich DNAs and RNAs containing guanine quartet as a fundamental unit. ${ }^{12}$ In the guanine quartet, four guanines from the same or from different DNA/RNA strands are connected via a special hydrogen bond network known as "Hoogsteen base pairing", where Gquadruplex is stabilized by coordination with alkali cations $\left(\mathrm{Na}^{+}, \mathrm{K}^{+}\right.$, or $\left.\mathrm{Li}^{+}\right) .{ }^{12,13}$ Interestingly, recent bioinformatic analyses have found that 376000 potential G-quadruplex-forming sequences exist in the human genome and more than $40 \%$ human gene promoters contain one or more quadruplex motifs. ${ }^{14}$ Strong evidences have also supported the presence of G-quadruplex motifs in vivo, for example in G-rich promoter element of the c-myc oncogene, VEGF, and telomeres. ${ }^{15}$

DNAzymes with peroxidase mimicking activity have been widely used for biorecognition events like DNA hybridization ${ }^{16}$ and formation of aptamer-substrate complexes. ${ }^{1,}{ }^{17}$ Gquadruplex/hemin catalyzes several oxidative reactions similar to classical HRP in the presence of $\mathrm{H}_{2} \mathrm{O}_{2}$, like oxidation of 2,2'-azino-bis(3-ethylbenzthiazoline-6-sulfonate dianion (ABTS ${ }^{2-}$ ) to colored ABTS ${ }^{--}$radical product. ${ }^{9}$ Willner and co-workers have proved that G-quadruplex/hemin complex can not only act as HRP mimetic but it can also mimick NADH oxidase and NADH peroxidase. ${ }^{9}$ G-quadruplex/hemin-based DNAzymes possess several distinct advantages over natural proteic peroxidases, including higher stability against hydrolysis and heat treatment, small size, simple synthesis, facile manipulation and amenability to rational design of allosteric control. $^{2}$ Therefore, G-quadruplex/hemin DNAzyme systems have been extensively used as a catalytic label as better alternative to HRP for amplified electrochemical detection. ${ }^{18}$ Though peroxidase mimicking DNAzymes is a promising alternative to natural HRP in biochemical 
sensing, its ability to oxidize and degrade the macromolecules or nanomaterials was not reported yet. Soon after the discovery of biodegradation carbon nanotubes (CNTs) by enzymatic catalysis of HRP, the potential of many other peroxidases or oxidative enzymes, including microbial enzymes, to degrade the various forms of carbon nanomaterials (CNMs) including graphene oxide has been uncovered. ${ }^{19-21}$ Indeed, many oxidative enzymes such as human myeloperoxidase (MPO) ${ }^{22}$ eosinophil peroxidase (EPO), ${ }^{23}$ manganese peroxidase (MnPO), ${ }^{24}$ lactoperoxidase, ${ }^{25}$ are capable to degrade CNMs. CNMs including CNTs and graphene-based materials are increasingly developed for industrial and biomedical applications. However, biodegradability of CNMs had raised serious concerns about their usage since there are many ways (occupational, environmental, or biomedical) through which CNMs could be exposed to humans. ${ }^{26}$ As HRP was able to degrade CNTs, ${ }^{19,}{ }^{20}$ or $\mathrm{GO},{ }^{27,} 28$ it would be very interesting to interrogate the ability of HRP-mimicking DNAzyme to oxidize or degrade CNMs, as a valuable alternative to HRP due to its robust catalytic activity and enhanced stability.

\section{Results and Discussion}

To prove the biodegradability of GO by DNAzymes, we have explored a nucleotide sequence reported previously. ${ }^{10,11}$ Sen and co-workers have developed an efficient DNAzyme based on the 18-nucleotide PS2.M 5'-GTG GGT AGG GCG GGT TGG-3' strand, which binds to Fe (III) heme or hemin, and it is able to catalyze the oxidation of thioanisole, indole and styrene substrates via 2-electron peroxidation reactions. ${ }^{10}$ The remarkable peroxidase activity of the PS2.M-hemin complex has been exploited in many promising applications including chemical sensing, electrochemistry, and immunoblotting. ${ }^{11}$ Herein, we interrogate whether PS2.M-hemin is capable to catalyze the oxidation and degradation of GO via 2-electron transfer mechanism similar to that of HRP. ${ }^{27,28}$ Two PS2.M-hemin complexes (named $1 \times$ complex and $3 \times$ complex) were prepared at different concentrations in a spectroscopic buffer (see Experimental section for its composition). The $1 \times$ complex contains $1 \mu \mathrm{M}$ Fe (III) heme and 3.0 $\mu \mathrm{M}$ PS2.M as optimized earlier. ${ }^{11}$ The $3 \times$ complex contains $3 \mu \mathrm{M}$ Fe (III) heme and $9.0 \mu \mathrm{M}$ PS2.M, respectively (see Experimental section for more details). The complex formation was confirmed by UV-vis absorption (Figure S1). The presence of $1 \times$ and $3 \times$ complexes was measured looking to the characteristic hyperchromicity of their Soret absorption bands and to the changes in their visible spectra compared to soluble monomeric Fe (III) heme in the absence of DNA (Figure S1). ${ }^{11}$ 
Interestingly, the formation of PS2.M-hemin complex was not affected by the presence of GO since the hyperchromic Soret absorption band of Fe (III) is still visible in both complexes (Figure S1). The peroxidase activity of PS2.M-hemin $1 \times$ and $3 \times$ complexes was tested qualitatively via oxidation of $\mathrm{ABTS}^{2-}$ to $\mathrm{ABTS}^{++}$radical cation (green color luminescence, Figure S2) in the presence of $\mathrm{H}_{2} \mathrm{O}_{2} \cdot{ }^{11,29}$ Further, ABTS ${ }^{++}$radical cation was not inhibited by the presence of GO since the green color luminescence of the $\mathrm{ABTS}^{.+}$radical remained unaltered (Figure S2), evidencing that the peroxidase activity of PS2.M-hemin complex was also active in the presence of GO sheets. Highly water-dispersible GO sheets used for the degradation experiments were synthesized using a modified Hummers method as reported previously (Figure 1A). ${ }^{30}$

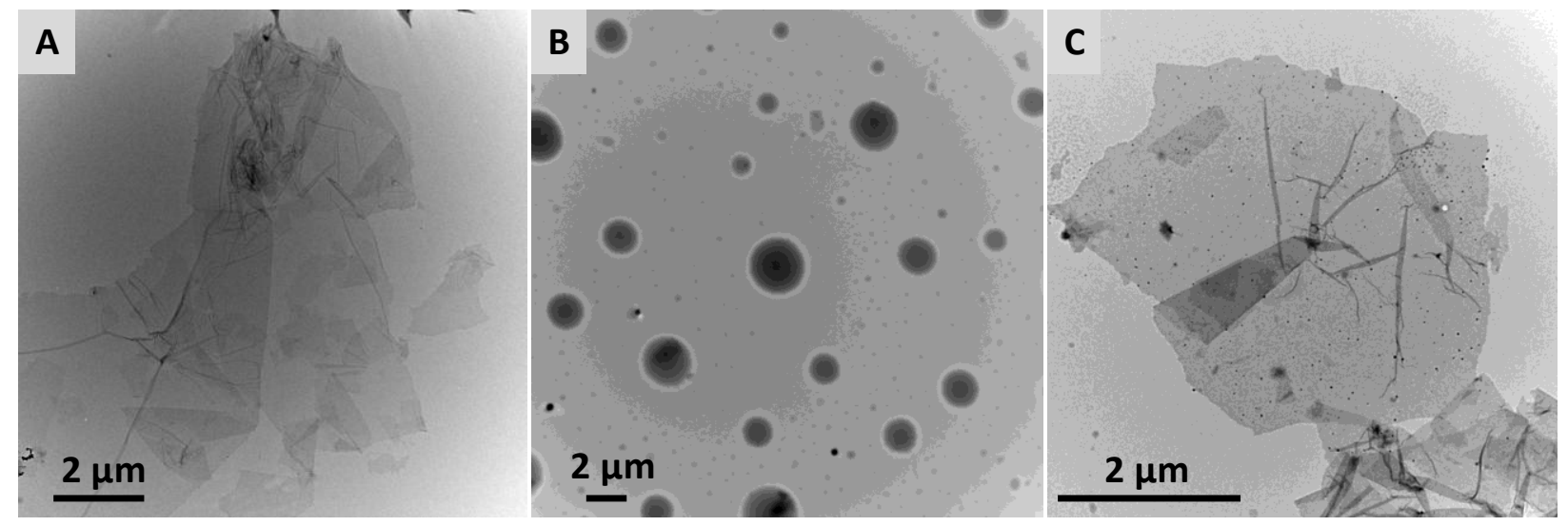

Figure 1. TEM images: (A) GO dispersed in water; (B) PS2.M-hemin 3× complex at day 0; (C) PS2.M-hemin $3 \times$ complex $+\mathrm{GO}$ at day 0 .

DNAzymes $1 \times$ and $3 \times$ complexes were prepared in $500 \mu \mathrm{L}$ of $2 \times$ buffer (see Experimental section for details) and milli- $\mathrm{Q}^{\circledR}$ water followed by addition of $10 \mu \mathrm{g}$ of GO after $30 \mathrm{~min}$ to both complexes. The peroxidase activity of $1 \times$ and $3 \times$ PS2.M-hemin complexes was triggered by adding $\mathrm{H}_{2} \mathrm{O}_{2}$ once per day up to 30 days. Three times higher concentration of $\mathrm{H}_{2} \mathrm{O}_{2}$ was added to $3 \times$ complex compared to $1 \times$ complex. At first, we employed transmission electron microscopy (TEM) to observe the morphological changes of GO sheets before and after the treatment with $1 \times$ and $3 \times$ PS2.M-hemin complexes. The two complexes without addition of GO form spherical particles, with the size of $3 \times$ complex larger than $1 \times$ complex particles (Figure $1 B$ and Figure S3A). After addition of GO to $3 \times$ complex, we observed a reduction of the dimension of the spherical particles adsorbed onto the surface of GO (Figure 1C and Figure S3C), while some of 
the particles were also found outside GO sheets (Figure S3B). In the case of $1 \times$ complex, the DNA particles were more difficult to see onto GO sheets (data not shown).
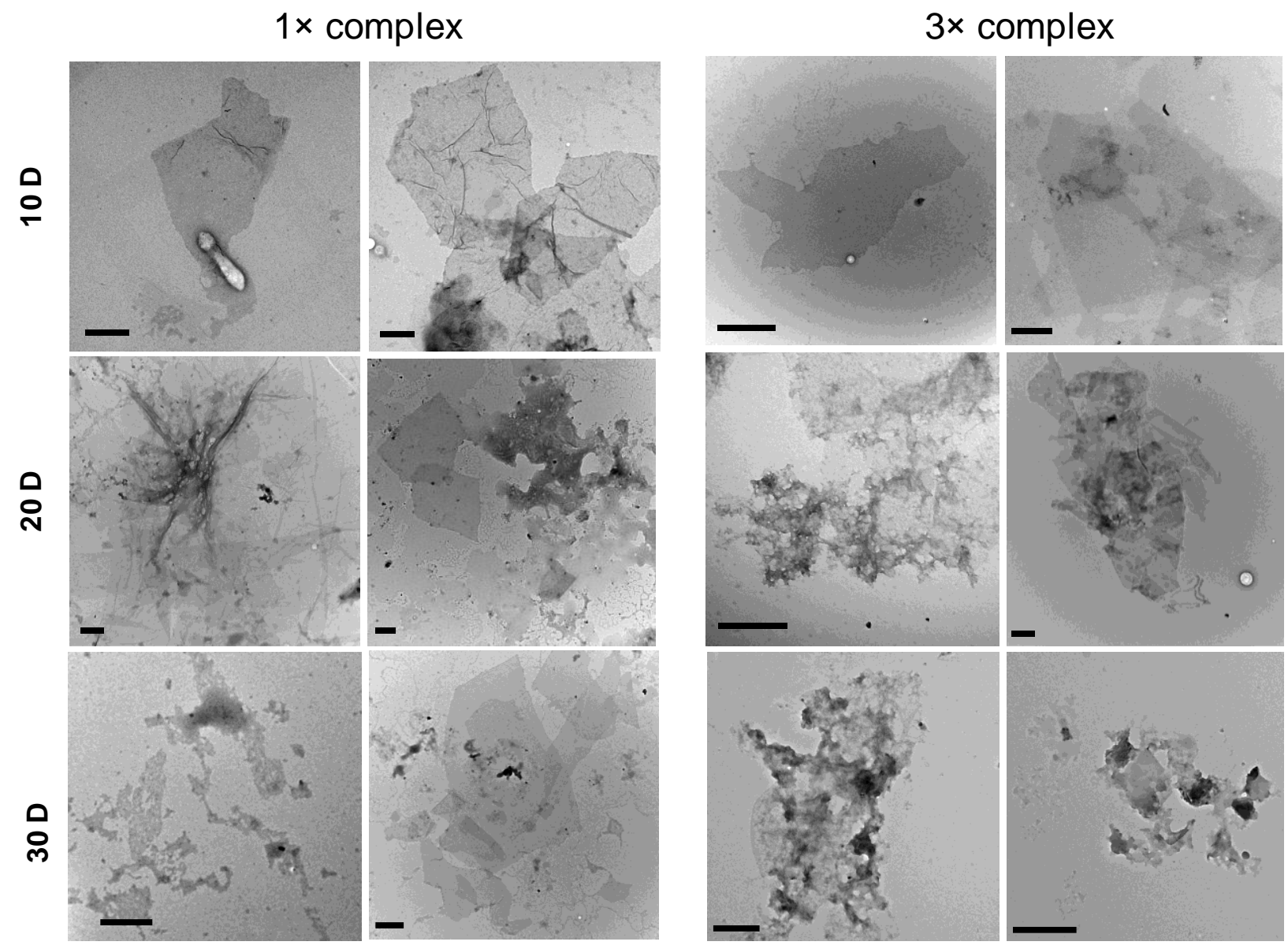

Figure 2. Degradation of GO sheets by $1 \times$ (left) and $3 \times$ (right) complex at different time points from 10 to 30 days. Scale bar: $500 \mathrm{~nm}$.

The degradation of GO sheets by DNAzymes was followed by TEM (Figure 2). In the case of $1 \times$ complex, the morphology of GO sheets did not clearly change after 10 day incubation. Continuing the treatment to 20 days few GO sheets started presenting porous structures. Large porous and fragmented sheets were instead observed after 30 days of incubation, although we could see GO sheets still intact. The $3 \times$ complex is more efficient in degrading GO as many broken and highly porous sheets were present in the TEM grid after 20 days (Figure 2). Although the degradation was not complete, many small fragments and debris were visible after 30 days. Therefore, $3 \times$ complex has a better oxidizing and degrading ability than $1 \times$ complex. On other hand, the control experiments using DNAzymes in the absence of hydrogen peroxide 
did not show changes in the morphology of GO sheets (Figure S4A and S5A). Another set of control experiments using hemin alone in the presence of $\mathrm{H}_{2} \mathrm{O}_{2}$ showed that this porphyrin is able to affect moderately the morphology of GO sheets after 30 days, but only in the case of the higher concentration $(3 \times)$ (Figure S4B and Figure S5B), due to the peroxidase activity of hemin itself. However, it has been previously found that DNAzymes (PS2.M-hemin complex) have peroxidase activity 250 times higher than the hemin substrate alone. ${ }^{10,31}$ Finally, the addition of only $\mathrm{H}_{2} \mathrm{O}_{2}$ once in a day for 30 days did not affect the morphology of GO sheets (Figure $\mathbf{S 4 C}$ ) as also proved in our previous reports. ${ }^{28,30}$

Next, we employed 2d Raman mapping monitoring the peak area of D and G bands of GO to get more insights about the degradation by PS2.M-hemin catalysis in the presence of $\mathrm{H}_{2} \mathrm{O}_{2}$. First, we analyzed GO sheets before and after incubation with $1 \times$ complex (Figure 3). At 0 day, the mapping of the $\mathrm{G}$ band shows a very strong signal (Figure 3, top left panel) relative to the $\mathrm{sp}^{2}$ carbon network, and highly intense D and G bands are present in the averaged spectra of the overall 2d map (Figure 3, top right panel). After 30 days, the $\mathrm{G}$ band signal (Figure 3, bottom left panel) dramatically decreased compared to $\mathrm{G}$ band at day 0 , suggesting extensive damage of $\mathrm{sp}^{2}$ network of GO. The analysis of the D/G ratio (Figure 3, middle panels) evidences a significant increase of its intensity after 30 day incubation compared to day 0. Moreover, the average of the Raman spectra (Figure 3, bottom right panel) shows that the G and D peaks almost disappeared confirming an wide degradation of GO sheets after 30 day incubation with $1 \times$ complex. 

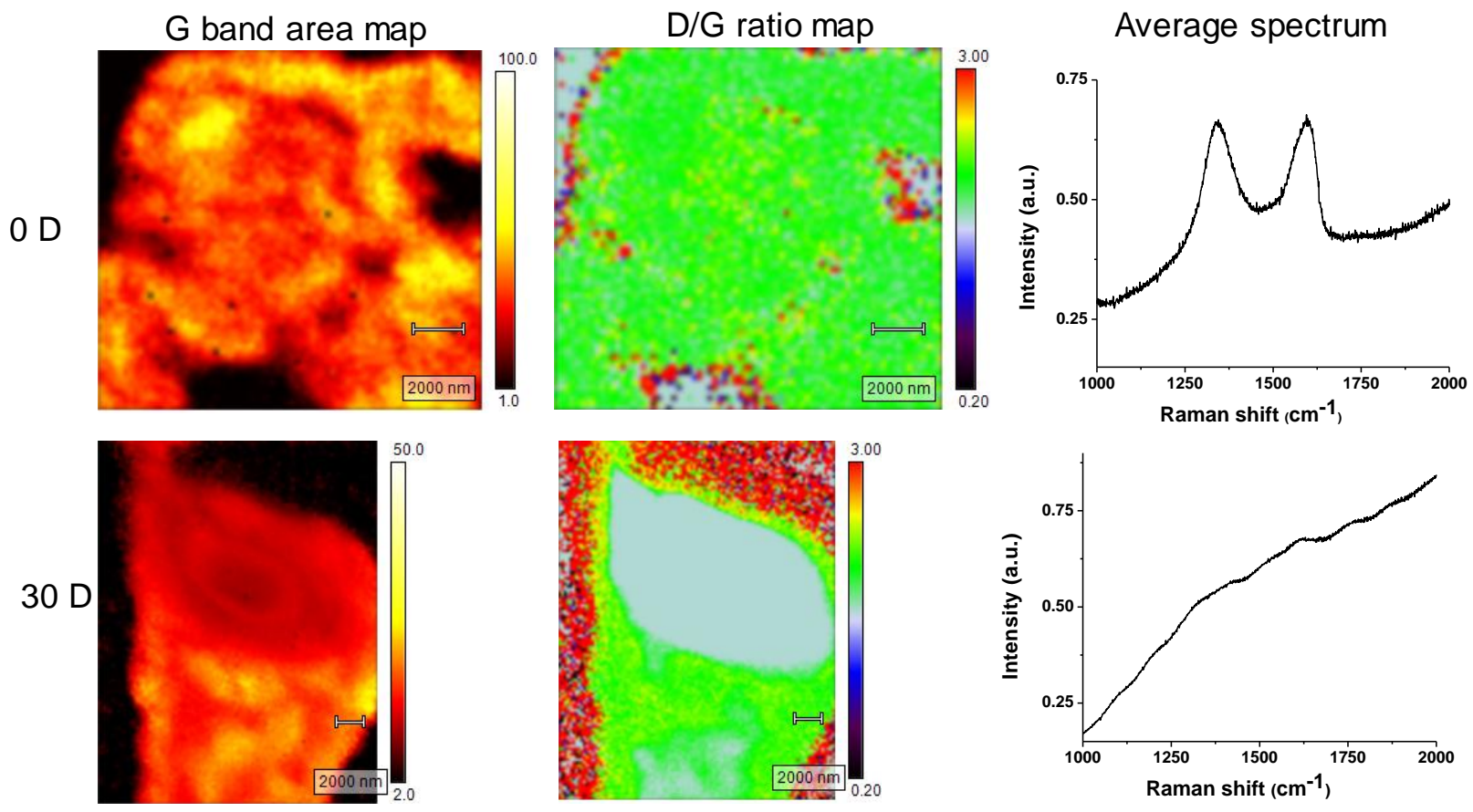

Figure 3. 2d Raman mapping of $1 \times$ complex incubated with GO sheets for 0 day (top panels) and 30 days (bottom panels) in the presence of hydrogen peroxide. The first image is the $\mathrm{G}$ band area map (red color); the second image is the D/G band ratio map (rain bow color) and the third image is the average spectra of all collected points.

In the case of GO sheets incubated with $3 \times$ complex (Figure 4), G band map has much lower intensity after 30 days compared to day 0 (Figure 4, bottom left panel), while D/G ratio strongly increased (Figure 4, middle panels). In addition, the average spectra of overall map show D and $\mathrm{G}$ bands with negligible intensity compared to 0 day (Figure 4, bottom right panel), suggesting the complete degradation of GO. From these data, we can conclude that higher damage of GO is occurring in the case of $3 \times$ complex over $1 \times$ complex. These results clearly support that $3 \times$ complex has better ability to degrade GO sheets than 1× complex. The Raman analyses are in full agreement with TEM data (Figure 2). 

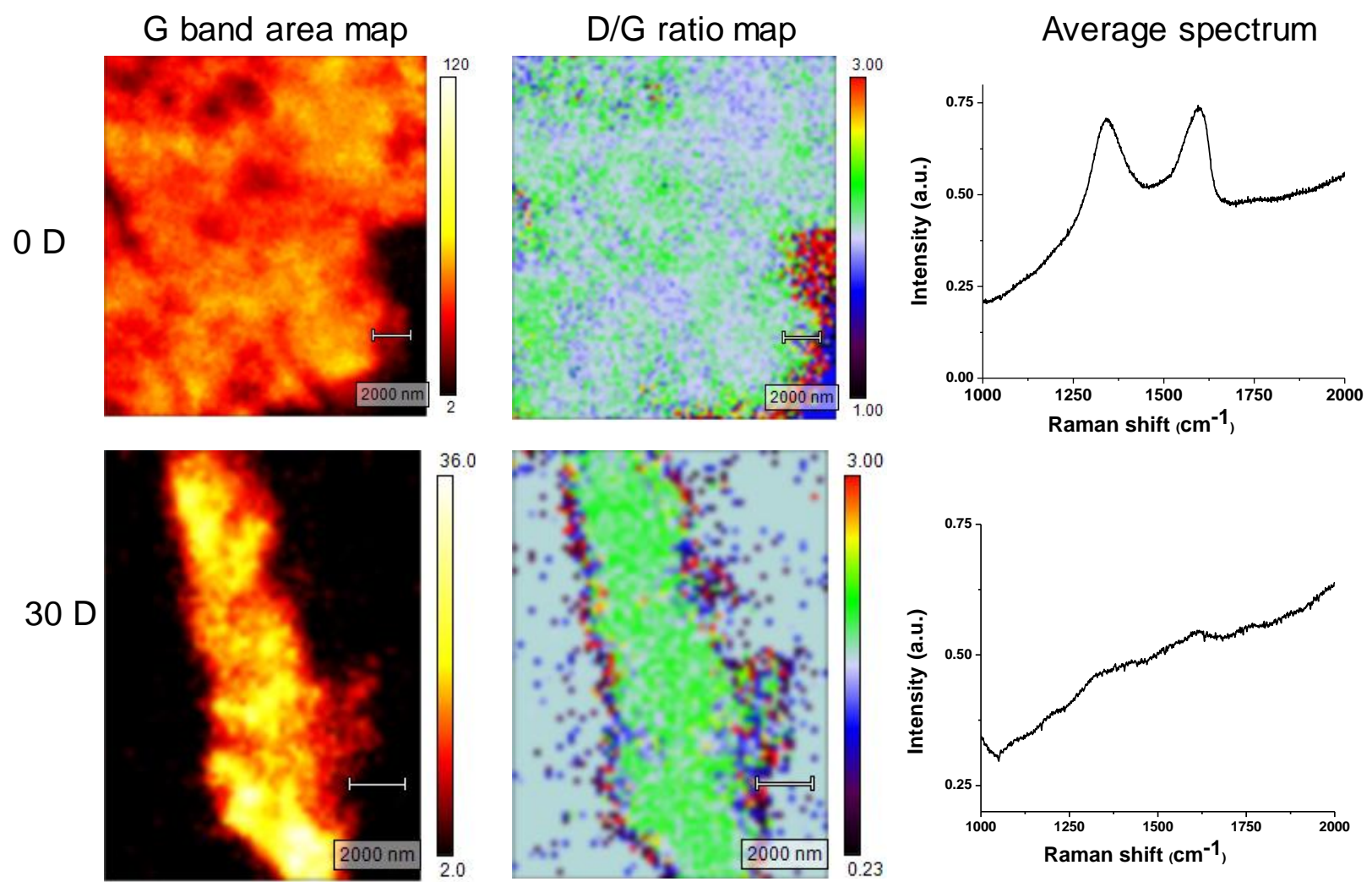

Figure 4. 2d Raman mapping of $3 \times$ complex incubated with GO sheets for 0 day (top panels) and 30 days (bottom panels) in the presence of hydrogen peroxide. The first image is the $\mathrm{G}$ band area map (red color); the second image is the D/G band ratio map (rain bow color) and the third image is the average spectra of all collected points.

Both TEM and Raman analyses are supporting that the degradation of GO is possible by the peroxidase activity of DNAzymes. These current results reveal that DNAzymes are able to oxidize and degrade not only smaller molecules like thioanisole, indole and styrene but also larger structures like graphene oxide ${ }^{11}$. Earlier studies proved that guanine-rich oligonucleotide PS2.M folds into a guanine quadruplex and acts as an apoenzyme for the hemin co-factor, ${ }^{18,} 32$ where oxidation is taken place via 2-electron oxidation mechanism (Figure S6) similar to the 2electron mechanism shown by natural hemin containing peroxidase enzymes like HRP or MPO. ${ }^{33}$ Thus, our data on degradation of GO sheets by PS2.M-hemin complex suggest that the enzymatic oxidation likely happened via 2 -electron mechanism by production of reactive oxygen intermediates (ROS) as explained earlier. ${ }^{33}$ Previous studies also proved that the enzymatic or peroxidase activity of PS2.M-hemin complex is nearly equal to the plant peroxidase HRP. ${ }^{3}$ The similar 2-electron oxidation mechanism by HRP is responsible of the degradation the graphene oxide as reported earlier. ${ }^{27,28}$ The time taken to degrade GO sheets (nearly 30 days in the case of 
$3 \times$ complex) is also similar to the time-frame activity of HRP. ${ }^{28}$ The reactive oxygen intermediates generated through G-quadruplex/hemin catalysis of hydrogen peroxide likely cause oxidation of the GO sheets at the edges and the defects, or at the level of the oxygen groups on the surface of GO. The reactive oxygen intermediates remove the hydroxyl and epoxide groups along with the cleavage of adjacent $\mathrm{C}-\mathrm{C}$ and $\mathrm{C}=\mathrm{C}$ bonds likely leading to the formation of several holey regions, and eventually leading to degradation of the GO as observed in Figure 2.

Our results on the degradation of GO sheets by Q-quadruplex/hemin catalysis is supported by a very recent work describing the cutting of single-walled carbon nanotubes to shorter tubes by DNA origami and G-quadruplex hybrid complexes. ${ }^{34}$ The reactive intermediates produced from decomposition of hydrogen peroxide by the G-quadruplex react with pristine SWCNTs randomly shortening the tubes. The DNA used to form this G-quadruplex is however different from that used in our work, and its catalytic cutting action seems faster (only 1 hour).

Based on the current results, we expect that DNAzymes could be also used to degrade other graphene-based materials such as reduced graphene oxide (rGO), pristine graphene, and other $2 \mathrm{D}$ materials. However, compared to GO, rGO and pristine graphene sheets have much strong resistance towards oxidation or degradation. Thus, longer incubation time or enhanced peroxidase activity, using for example peptide conjugated DNAzymes, ${ }^{29}$ could better degrade these materials. In addition, it was recently reported that DNA sequences containing $\mathrm{d}(\mathrm{CCC})$, flanked on both ends of the G4-core remarkably enhanced their DNAzyme activity. ${ }^{35}$

\section{Conclusion}

Our work demonstrates that PS2.M-hemin complex represents an interesting system with an efficient peroxidase activity able to degrade large materials like graphene oxide, similarly to classical HRP. This study opens new possibilities in the design of better artificial oxidative enzymes for eliminating carbon nanomaterials. As the G-quadruplexes are present in the human genome, our results may also give new insights in the conception of hybrid systems capable to degrade graphene in the body in synergy with naturally occurring peroxidases, such as MPO, secreted by activated immune cells. ${ }^{36}$ 


\section{Experimental Section}

Reagents. PS2.M (5'-GTG GGT AGG GCG GGT TGG-3') was purchased from Integrated DNA Technologies Inc. PS2.M stock solution was prepared by dissolving the oligonucleotide in TE buffer [10 mM Tris, $\mathrm{pH} 7.5$, and $0.1 \mathrm{mM}$ ethylenediaminetetraacetate (EDTA)] and stored in the freezer at $-20{ }^{\circ} \mathrm{C}$. Triton X-100 and EDTA were purchased from Sigma-Aldrich. HEPES, MES [(2-(N-morpholino)ethanesulfonic acid)], DMF, $\mathrm{KCl}, \mathrm{NH}_{4} \mathrm{OH}, \mathrm{Fe}(\mathrm{III})$ heme (hemin) and hydrogen peroxide (30\% aqueous solution) were purchased from Alfa Aesar and used directly without any further purification

G-quadruplex (PS2.M)-hemin complex formation. Thirty-two $\mu \mathrm{L}$ of a $100 \mu \mathrm{M}$ PS2.M stock solution in TE buffer and $10 \mu \mathrm{L}$ of $100 \mu \mathrm{M}$ hemin in DMF were added to $500 \mu \mathrm{L}$ of a $2 \times$ buffer (80 mM HEPES- $\mathrm{NH}_{4} \mathrm{OH}, \mathrm{pH} 8.0,40 \mathrm{mM} \mathrm{KCl}, 0.1 \%$ Triton $\mathrm{X}-100$, and $2 \% \mathrm{DMF}$ ) in a $1.5 \mathrm{~mL}$ glass vial. Then milli- $\mathrm{Q}^{\circledR}$ water $(432 \mu \mathrm{L})$ was added to reach a volume of $980 \mu \mathrm{L}$. The solution was incubated for $5 \mathrm{~min}$ at room temperature to allow PS2.M-hemin interaction, This PS2.Mhemin complex is defined as $1 \times$ complex.

After the formation of the complex, $10 \mu \mathrm{L}$ of $\mathrm{GO}$ (corresponding to $10 \mu \mathrm{g}$ GO dispersed in milliQ water) were added to the solution. The catalytic reaction was initiated by adding $10 \mu \mathrm{L}$ of $100 \mathrm{mM} \mathrm{H}_{2} \mathrm{O}_{2}$. Nine $\mu \mathrm{L}$ of $100 \mathrm{mM} \mathrm{H}_{2} \mathrm{O}_{2}$ were then added everyday day up to 30 days. Aliqotes of $50 \mu \mathrm{L}$ were taken at 0 day, 10,20 and 30 days and stored in the cold room at $-15{ }^{\circ} \mathrm{C}$ before analysis.

The control experiments were carried out using a similar procedure and with the following conditions: Control 1: PS2.M-hemin $+10 \mu \mathrm{L}$ of GO (10 $\mu \mathrm{g}$ of GO) without addition of $\mathrm{H}_{2} \mathrm{O}_{2}$ up to 30 days. Control 2: Hemin alone $+10 \mu \mathrm{L}$ of GO (10 $\mu$ g of GO) + daily addition of $\mathrm{H}_{2} \mathrm{O}_{2}$ up to 30 days. Control 3: PS2.M alone, without hemin, $\mathrm{GO}$ and $\mathrm{H}_{2} \mathrm{O}_{2}$ to check the stability of Gquadruplex up to 30 days. Control 4: $\mathrm{GO}(10 \mu \mathrm{g} \mathrm{GO})$ alone and daily addition of $\mathrm{H}_{2} \mathrm{O}_{2}$ up to 30 days.

Formation of PS2.M-hemin $3 \times$ complex. $3 \times$ complex of PS2.M-hemin was formed by adding PS2.M and hemin at a concentration 3 times higher than $1 \times$ complex. Ninety-six $\mu \mathrm{L}$ of a 100 $\mu \mathrm{M}$ PS2.M stock in TE buffer and $30 \mu \mathrm{L}$ of $100 \mu \mathrm{M}$ hemin in DMF were added to $500 \mu \mathrm{L}$ of a $2 \times$ buffer ( $80 \mathrm{mM}$ HEPES- $\mathrm{NH}_{4} \mathrm{OH}, \mathrm{pH} 8.0,40 \mathrm{mM} \mathrm{KCl}, 0.1 \%$ Triton $\mathrm{X}-100$, and $2 \% \mathrm{DMF}$ ) in a $1.5 \mathrm{~mL}$ glass vial. Then milli-Q water $(364 \mu \mathrm{L})$ was added to reach a volume of $980 \mu \mathrm{L}$. The solution was incubated for $5 \mathrm{~min}$ at room temperature to allow PS2.M-hemin interaction. After 
the formation of the complex, $10 \mu \mathrm{L}$ of GO (corresponding to $10 \mu \mathrm{g}$ GO dispersed in milli- ${ }^{\circledR}$ water) were added to the solution. The catalytic reaction was initiated by adding $10 \mu \mathrm{L}$ of 100 $\mathrm{mM} \mathrm{H} \mathrm{O}_{2}$. Nine $\mu \mathrm{L}$ of $100 \mathrm{mM} \mathrm{H}_{2} \mathrm{O}_{2}$ were then added everyday day up to 30 days. Aliqotes of $50 \mu \mathrm{L}$ were taken at 0 day, 10, 20 and 30 days and stored in the cold room at $-15^{\circ} \mathrm{C}$ before analysis.

TEM analysis. Six $\mu \mathrm{L}$ of each aliquot was deposited on carbon coated copper grid and dried under the lamp. The grids were washed by the milli- $Q^{\circledR}$ water for $15-20$ min to remove the salts from buffer. All the samples were analyzed by a Hitachi H7500 microscope (Tokyo, Japan) with an accelerating voltage of $80 \mathrm{kV}$, equipped with an AMT Hamamatsu camera (Tokyo, Japan).

2d Raman mapping analysis. 2d Raman mapping analyses of all GO samples were performed using a Renishaw inVia micro-Raman equipped with $532 \mathrm{~nm}$ laser along with Leica microscope. All 2d maps were recorded with $1 \%$ laser power using $50 \times$ objective lens and 0.1 sec laser exposure. All samples were prepared by drop-casting $10 \mu \mathrm{L}$ of respective samples on a Silicon wafer coated with $\mathrm{SiO}_{2}(20 \mathrm{~nm}$, TED Pella) and dried for $24 \mathrm{~h}$ at room temperature. The intensity of the $2 \mathrm{~d}$ maps was normalized and cosmic rays were removed using Wire 4.2 software.

UV-vis spectroscopy. UV-vis studies were performed by following an earlier report, ${ }^{11}$ where 1 $\mathrm{mL}$ of solution containing $1 \mu \mathrm{M}$ PS2.M and $0.5 \mu \mathrm{M}$ Fe(III) hemin in spectroscopy buffer [50 mM MES (2-(N-morpholino)ethanesulfonic acid), $\mathrm{pH} 6.2,100 \mathrm{mM}$ Tris-acetate, $20 \mathrm{mM}$ potassium acetate, $0.05 \%$ Triton $\mathrm{X}-100,1 \% \mathrm{DMF}$ ] were incubated for $30 \mathrm{~min}$ at room temperature to permit PS2.M-hemin interaction. The UV-vis spectra of PS2.M-hemin $1 \times$ and $3 \times$ complexes, PS2.M and hemin were obtained using a Cary $5000 \mathrm{UV}$-vis spectrophotometer. Background from the buffer was subtracted from the sample spectra. One $\mu \mathrm{L}$ of GO $(1 \mu \mathrm{g} / \mu \mathrm{L})$ dispersed in milli- $Q^{\circledR}$ water was added to the PS2.M-hemin $1 \times$ and $3 \times$ complexes and the spectra were recorded. The UV-vis spectrum of $1 \mu \mathrm{g} / \mu \mathrm{L}$ of GO alone in the spectroscopy buffer was also measured.

ABTS peroxidase test. Qualitative peroxidase test of $1 \times$ and $3 \times$ complexes was carried out using ABTS reagent via oxidation of $\mathrm{ABTS}^{2-}$ to $\mathrm{ABTS}^{++}$radical cation (green color luminescence). ${ }^{29}$ The two complexes were prepared in $500 \mu \mathrm{L}$ of $2 \times$ buffer $(80 \mathrm{mM}$ HEPES$\mathrm{NH}_{4} \mathrm{OH}, \mathrm{pH} 8.0,40 \mathrm{mM} \mathrm{KCl}, 0.1 \%$ Triton $\mathrm{X}-100$, and 2\% DMF) and milli-Q ${ }^{\circledR}$ water as described above. An equal amount of $100 \mathrm{mM}$ ABTS $(10 \mu \mathrm{L})$ and $100 \mathrm{mM} \mathrm{H}_{2} \mathrm{O}_{2}(10 \mu \mathrm{L})$ was added to test the peroxidase activity. Similarly, qualitative peroxidase activity was also tested 
using ABTS reagent for the two complexes in the presence of $10 \mu \mathrm{L}$ of GO added after $30 \mathrm{~min}$. An equal amount of $100 \mathrm{mM}$ ABTS $(10 \mu \mathrm{L})$ and $100 \mathrm{mM} \mathrm{H}_{2} \mathrm{O}_{2}(10 \mu \mathrm{L})$ was added to test the peroxidase activity as shown in Figure S2.

\section{Conflict of interest}

There are no conflicts to declare

\section{Acknowledgements}

This work was supported by EU Commission through the GRAPHENE Flagship project (no. 696656 and no. 785219), and by the Agence Nationale de la Recherche (ANR) through the LabEx project Chemistry of Complex Systems (ANR-10-LABX-0026_CSC). The authors wish to thank V. Palermo and E. Treossi for providing graphene oxide sample, and C. Royer and V. Demais for TEM analyses at the Plateforme Imagerie in Vitro at the Center of Neurochemistry (Strasbourg, France). Dedicated to Prof. Maurizio Prato on the occasion of his $65^{\text {th }}$ birthday.

Electronic supplementary information (ESI) is available at doi:

\section{References and Notes}

1. E. Sharon, R. Freeman and I. Willner, Anal. Chem., 2010, 82, 7073-7077.

2. W. Li, Y. Li, Z. Liu, B. Lin, H. Yi, F. Xu, Z. Nie and S. Yao, Nucleic Acids Res., 2016, 44, 7373-7384.

3. P. Travascio, P. K. Witting, A. G. Mauk and D. Sen, J. Am. Chem. Soc., 2001, 123, 13371348.

4. R. R. Breaker, Nat. Biotechnol., 1997, 15, 427-431.

5. M. Hollenstein, Molecules, 2015, 20, 20777-20804.

6. S. K. Silverman, Angew. Chem. Int. Ed., 2010, 49, 7180-7201.

7. J. Kosman and B. Juskowiak, Anal. Chim. Acta, 2011, 707, 7-17.

8. P. Travascio, A. J. Bennet, D. Y. Wang and D. Sen, Chem. Biol., 1999, 6, 779-787.

9. E. Golub, R. Freeman and I. Willner, Angew. Chem. Int. Ed., 2011, 50, 11710-11714.

10. P. Travascio, Y. Li and D. Sen, Chem. Biol., 1998, 5, 505-517.

11. L. C. H. Poon, S. P. Methot, W. Morabi-Pazooki, F. Pio, A. J. Bennet and D. Sen, J. Am. Chem. Soc., 2011, 133, 1877-1884.

12. O. J. Einarson and D. Sen, Nucleic Acids Res., 2017, 45, 9813-9822. 
13. R. K. Ralph, W. J. Connors and H. G. Khorana, J. Am. Chem. Soc., 1962, 84, 2265-2266.

14. X. Cheng, X. Liu, T. Bing, Z. Cao and D. Shangguan, Biochemistry, 2009, 48, 78177823.

15. A. K. Todd, M. Johnston and S. Neidle, Nucleic Acids Res., 2005, 33, 2901-2907.

16. Y. Xiao, V. Pavlov, R. Gill, T. Bourenko and I. Willner, ChemBioChem, 2004, 5, 374379.

17. D. Li, B. Shlyahovsky, J. Elbaz and I. Willner, J. Am. Chem. Soc., 2007, 129, 5804-5805.

18. X.-Z. F. Guo-Cheng Han, Zhencheng Chen, Int. J. Electrochem. Sci., 2015, 10, 38973913.

19. B. L. Allen, P. D. Kichambare, P. Gou, I. I. Vlasova, A. A. Kapralov, N. Konduru, V. E. Kagan and A. Star, Nano Lett., 2008, 8, 3899-3903.

20. B. L. Allen, G. P. Kotchey, Y. Chen, N. V. K. Yanamala, J. Klein-Seetharaman, V. E. Kagan and A. Star, J. Am. Chem. Soc., 2009, 131, 17194-17205.

21. I. I. Vlasova, A. A. Kapralov, Z. P. Michael, S. C. Burkert, M. R. Shurin, A. Star, A. A. Shvedova and V. E. Kagan, Toxicol. Appl. Pharmacol., 2016, 299, 58-69.

22. V. Kagan, N. Konduru, W. Feng, B. Allen, J. Conroy, Y. Volkov, I. Vlasova, N. Belikova, N. Yanamala, A. Kapralov, Y. Tyurina, J. Shi, E. Kisin, A. Murray, J. Franks, D. Stolz, P. Gou, J. Klein-Seetharaman, B. Fadeel, A. Star and A. Shvedova, Nat. Nanotechnol., 2010, 5, 354 - 359.

23. F. T. Andõn, A. A. Kapralov, N. Yanamala, W. Feng, A. Baygan, B. J. Chambers, K. Hultenby, F. Ye, M. S. Toprak, B. D. Brandner, A. Fornara, J. Klein-Seetharaman, G. P. Kotchey, A. Star, A. A. Shvedova, B. Fadeel and V. E. Kagan, Small, 2013, 9, 27212729.

24. C. Zhang, W. Chen and P. J. J. Alvarez, Environ. Sci. Technol., 2014, 48, 7918-7923.

25. K. Bhattacharya, R. El-Sayed, F. T. Andón, S. P. Mukherjee, J. Gregory, H. Li, Y. Zhao, W. Seo, A. Fornara, B. Brandner, M. S. Toprak, K. Leifer, A. Star and B. Fadeel, Carbon, 2015, 91, 506-517.

26. Z. Wang, W. Zhu, Y. Qiu, X. Yi, A. von dem Bussche, A. Kane, H. Gao, K. Koski and R. Hurt, Chem. Soc. Rev., 2016, 45, 1750-1780.

27. G. P. Kotchey, B. L. Allen, H. Vedala, N. Yanamala, A. A. Kapralov, Y. Y. Tyurina, J. Klein-Seetharaman, V. E. Kagan and A. Star, ACS Nano, 2011, 5, 2098-2108.

28. K. Rajendra, B. Fanny, R. Julie, S. Adukamparai Rajukrishnan, M.-M. Cécilia, K. Kostas and B. Alberto, 2D Mater., 2018, 5, 015020.

29. L. Xiao, Z. Zhou, M. Feng, A. Tong and Y. Xiang, Bioconj. Chem., 2016, 27, 621-627.

30. R. Kurapati, J. Russier, M. A. Squillaci, E. Treossi, C. Ménard-Moyon, A. E. Del RioCastillo, E. Vazquez, P. Samorì, V. Palermo and A. Bianco, Small, 2015, 11, 3985-3994. 
31. S. Narges, H. Saman, K. Khosro and R. Bijan, Biopolymers, 2017, 107, e23028.

32. H. J. Lipps and D. Rhodes, Trends Cell Biol., 2009, 19, 414-422.

33. G. P. Kotchey, S. A. Hasan, A. A. Kapralov, S. H. Ha, K. Kim, A. A. Shvedova, V. E. Kagan and A. Star, Acc. Chem. Res., 2012, 45, 1770-1781.

34. H. Atsumi and A. M. Belcher, ACS Nano, 2018, 12, 7986-7995.

35. T. Chang, H. Gong, P. Ding, X. Liu, W. Li, T. Bing, Z. Cao and D. Shangguan, Chem. Eur. J., 2016, 22, 4015-4021.

36. K. Rajendra, S. P. Mukherjee, C. Martín, G. Bepete, E. Vázquez, A. Penicaud, B. Fadeel and A. Bianco, Angew. Chem. Int. Ed., 2018, 57, 11722-11727. 